\title{
Should Empyema with or without Necrotizing Pneumonia in Children Be Managed Differently?
}

\author{
Karine Anastaze Stelle1, Anne Mornand', Nadia Bajwa', Isabelle Vidal'3 , Mehrak Anooshiravani', \\ Aikaterini Kanavaki ${ }^{4}$, Constance Barazzone Argiroffo ${ }^{1}$, Sylvain Blanchon ${ }^{1}$
}

${ }^{1}$ Pediatric Pulmonology Unit, Department of Pediatrics, University Hospital Geneva, Geneva, Switzerland

${ }^{2}$ Division of General Pediatrics, Department of Pediatrics, University Hospital Geneva, Geneva, Switzerland

${ }^{3}$ Division of Pediatric Surgery, Department of Pediatrics, University Hospital Geneva, Geneva, Switzerland

${ }^{4}$ Pediatric Radiology Unit, Department of Pediatrics, University Hospital Geneva, Geneva, Switzerland

Email: Karine.anastazestelle@gmail.com

How to cite this paper: Anastaze Stelle, K., Mornand, A., Bajwa, N., Vidal, I., Anooshiravani, M., Kanavaki, A., Barazzone Argiroffo, C. and Blanchon, S. (2017) Should Empyema with or without Necrotizing Pneumonia in Children Be Managed Differently? Health, 9, 209-222.

https://doi.org/10.4236/health.2017.92014

Received: December 9, 2016

Accepted: January 22, 2017

Published: January 25, 2017

Copyright $\odot 2017$ by authors and Scientific Research Publishing Inc. This work is licensed under the Creative Commons Attribution International License (CC BY 4.0).

http://creativecommons.org/licenses/by/4.0/

\begin{abstract}
Background: Necrotizing pneumonia (NP) is an increasing lung infection mostly associated with pleural empyema. Objectives: We aimed to compare children with empyema with and without concomitant NP, in terms of risk factors, management and outcome. Methods: We retrospectively included children hospitalized between 2005-2014 with empyema to whom a computed tomography was performed. We recorded patient characteristics, clinical, biological (blood and pleural fluid) and radiological findings, medical and surgical treatments, and clinical, radiological and functional follow-up. Results: 35 children with empyema were included, including 25 with a concomitant NP. Patients with or without NP were undistinguishable, in terms of characteristics, symptoms at admission or detected pathogens. Pleural leucocytes were significantly higher in the empyema group $(p=0.0002)$ as pleural LDH $(\mathrm{p}=0.002)$, and pleural/blood LDH ratio $(\mathrm{p}=0.0005)$. Medical and surgical managements were similar between both groups. Complications occurred in $1 / 10$ children with empyema alone (pneumatocele) and 5/25 with concomitant NP (bronchopleural fistula $(\mathrm{n}=3)$, lobectomy, pneumothorax). The hospital length of stay and delay for chest X-ray normalization were similar in both groups. Conclusion: Except for minor biological parameters, the presence of concomitant NP in case of empyema does not change the presentation, clinical features, management and outcome, suggesting that the presence of additional NP to empyema should not be managed differently. Therefore, in case of empyema with suspected concomitant NP, chest CT should probably be restricted to abnormal worsening or when mandatory for surgical treatment.
\end{abstract}




\section{Keywords}

Children, Necrotizing Pneumonia, Empyema

\section{Introduction}

Necrotizing pneumonia (NP) is a fairly rare but increasing lung infection mostly associated with pleural empyema (94\% - 97\%) [1]-[6].

NP is characterized by a loss of architecture and pulmonary tissue associated with the formation of thin-walled cavities full of air or liquid without enhancing border [7]. The physiopathology of NP is not yet completely understood, as the reason for its increasing incidence. Some authors argue a selection of more virulent serotypes of Streptococcus pneumoniae [1] [2] [4] [8] [9] [10], or a better identification of NP considering the easier resort to chest computed tomography (CT) [1] [11] [12]. Others theorized that a raising virulence of Staphylococcus aureus, especially when producing Panton-Valentine leukocidin (PVL) known to induce cellular lysis, is responsible for the increasing incidence of NP [13] [14]. But this last hypothesis seems doubtful as Staphylococcus aureus is implicated in only $2 \%$ to $32 \%$ of empyema [3] [4] [6] [12] [15].

There are only few studies focusing on empyema with NP that have been published [2] [5] [16] [17] [18] [19]. Macedo et al. reported, among patients with empyema, prolonged duration of pleural drainage and hospital length of stay in case of concomitant NP [18], while other authors found no difference [17] [19]. In 2012, the American Pediatric Surgical Association (APSA) published a review on the management of empyema and pointed out, that in case of NP, "there are no published data informing the choice of treatment for this specific condition" [16].

These discordant results regarding empyema with NP led us to compare risk factors, management and outcomes of children with pleural empyema with or without concomitant NP.

\section{Patients and Methods}

We performed a retrospective study at the University Children's Hospital of Geneva (Switzerland). From the institutional diagnosis registration (CIM10), we selected all children below 16-years old hospitalized between the $1^{\text {st }}$ January 2005 and the $31^{\text {st }}$ December 2014 with the diagnosis of pleural effusion and an available chest CT. All medical records were reviewed by two physicians (AS.K and B.S), in order to only include patients with a confirmed diagnosis of empyema, based on Hardie's criteria [20]. Diagnosis of concomitant NP was confirmed by two certified paediatric radiologists (A.M, K.A) who blindly reviewed all CT, according to published criteria of Donelly et al. [21]. CT was mostly performed because of clinical worsening, otherwise because of suspicion of parenchymal necrosis on standard chest X-ray or on surgeon request before procedures. 
Among 102 selected children with pleural effusion during the inclusion period to whom a CT was performed, we finally included 35 patients with a confirmed empyema: 25 patients had a concomitant NP (empyema + NP group) and 10 patients had empyema alone (empyema group), as illustrated in the CT images in Figure 1.

We excluded all patients from whom the CT was missing in order to avoid any undiagnosed NP in the empyema group. The design of the study and the flowchart of patient inclusions are summarized in Figure 2.

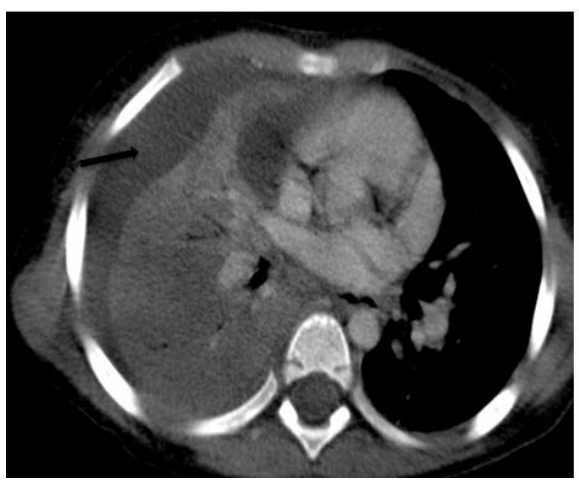

(a)

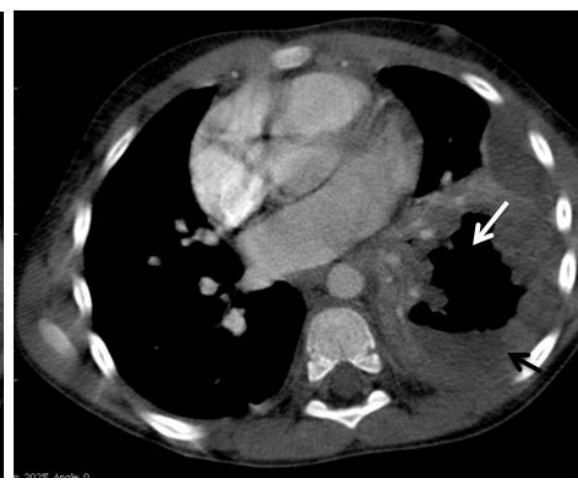

(b)

Figure 1. Contrast enhanced axial chest CT images. Left panel (a): pleural effusion (black arrow) and enhancing lung consolidation with no sign of cavitation. Right panel (b): pleural effusion (black arrow) and adjacent non-enhancing parenchyma with a large cavitary necrosis suggesting necrotizing pneumonia (white arrow).

102 children (0-16y.) hospitalized with pneummonia and pleural effusion between 2005 and 2014

67 patients excluded

(no Hardie's criteria $(n=53)$ or no available CT $(n=14))$

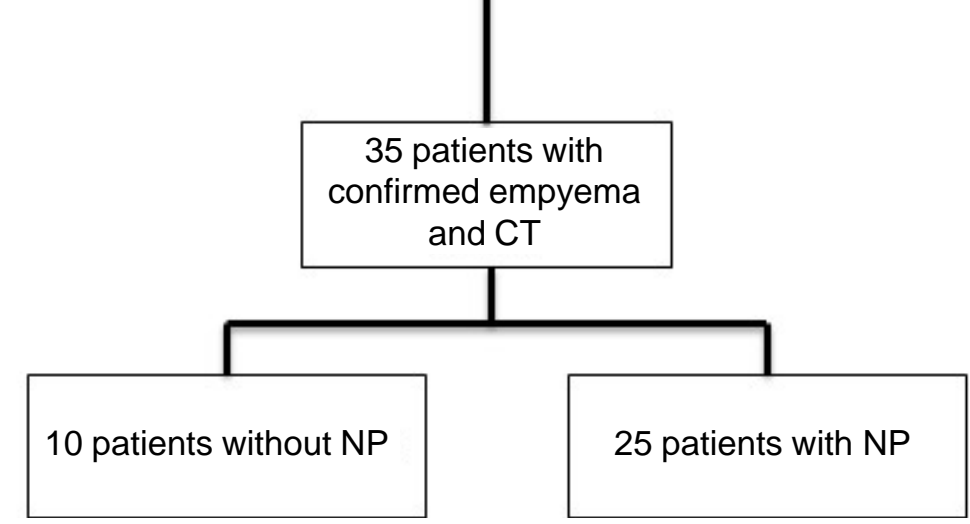

Figure 2. Design study. NP: Necrotizing pneumonia, CT: computed tomography. 
Collected data were age, gender, past medical history, underlying disease, clinical features at admission, biological findings (blood and pleura), chest imaging (X-ray and $\mathrm{CT}$ ), pathogens, medical and surgical management, and outcomes (oxygenotherapy, chest tube duration, surgery, fever duration, Intensive Care Unit (ICU) and hospital length of stay, radiological (at 6 and 12 months) and functional follow-up).

No supplemental examination and visit, blood test, CT or lung function test, were required for this study. The Ethical Committee of the University Hospital of Geneva approved this study on $04^{\text {th }}$ July 2012 (CER12-116R).

Results were expressed as median [range] or number (percentage) unless indicated. To compare patients presenting empyema with or without concomitant NP, Fisher's test was applied to categorical factors and Mann-Whitney $U$ test to continuous factors. Confidence interval was $95 \%$ and p-value $<0.05$ was considered significant. The time to X-ray normalization was assessed using KaplanMeier estimate of survival for interval-censored data since the date of normalization likely occurred between two visits [22].

\section{Results}

Patient characteristics and clinical features at admission are summarized in Table 1; there was no difference between the two groups. Past pulmonary medical history was only found in four patients from the empyema + NP group, including bacterial pneumonia $(\mathrm{n}=1)$ and viral bronchitis or bronchiolitis $(\mathrm{n}=3)$. Besides pulmonary diagnoses, one patient from the empyema group presented an hydronephrosis. The median delay time from first symptoms to admission was five days in both groups (from 1 to 5 days in the empyema group and from 0 to 9 days in the empyema + NP group).

Except one patient in the empyema + NP group, all patients underwent blood sample at admission and pleural fluid analysis. The pleural fluid was obtained by thoracocentesis ( 3 patients in the empyema group and 7 in the empyema $+\mathrm{NP}$ group), or during surgical insertion of a chest tube. The results of blood and pleural fluid tests are presented in Table 2. Regarding the blood tests at admission, including white cell count and inflammatory markers such as $\mathrm{C}$ reactive protein, we found no difference between the two groups. In the pleural fluid, white blood cells (WBC) and lactate dehydrogenase (LDH) were significantly lower in the empyema + NP group as well as pleura/blood LDH ratio. The pathogens were identified in the pleural fluid for all patients except one in the empyema + NP group (identified in the broncho-alveolar lavage). The involved micro-organisms are described in Table 2 and no difference was found between both groups regarding the proportion or type of pathogens, or the way to identify them.

The medical and surgical management, summarized in Table 3, was not different between the two groups, except the fibrinolytic agents more prescribed in the empyema group $(\mathrm{p}=0.047)$. The initial intravenous antibiotherapy was modified for three patients in the empyema group and seven patients in the 
Table 1. Patient characteristics and clinical features at admission. Data are expressed as median [range] or $\mathrm{n}(\%)$.

\begin{tabular}{|c|c|c|c|}
\hline & $\begin{array}{c}\text { Empyema } \\
\mathrm{n}=10\end{array}$ & $\begin{array}{c}\text { Empyema }+\mathrm{NP} \\
\mathrm{n}=\mathbf{2 5}\end{array}$ & p-value \\
\hline Age (year) & $3.0[0.6$ to 8.1$]$ & $3.6[0.8$ to 10.2$]$ & 0.99 \\
\hline Gender female & $2 / 10(20.0 \%)$ & $11 / 25(44.0 \%)$ & 0.26 \\
\hline Weight (standard deviation) & $0.25[-1.50$ to 3.00$]$ & $0.25[-1.50$ to 3.00$]$ & 0.59 \\
\hline Past pulmonary medical history & $0(0.0 \%)$ & $4 / 25(16.0 \%)$ & 0.30 \\
\hline Concomitant extra-pulmonary infection & $3 / 10(30.0 \%)$ & $6 / 25(24.0 \%)$ & 0.69 \\
\hline $\begin{array}{l}\text { Anti-pneumococcal vaccine } \\
\text { pneumocoquevaccine }=\text { yes }=1,2,3\end{array}$ & $3 / 10(30.0 \%)$ & $11 / 21(52.4 \%)$ & 0.28 \\
\hline \multicolumn{4}{|l|}{ Symptoms } \\
\hline Fever & 9/9 (100.0\%) & $24 / 25(96.0 \%)$ & 1 \\
\hline Cough & $5 / 10(50.0 \%)$ & $20 / 25(80.0 \%)$ & 0.11 \\
\hline Dyspnea & $2 / 10(20.0 \%)$ & $5 / 25(20.0 \%)$ & 1 \\
\hline Lethargy & $9 / 10(90.0 \%)$ & $22 / 25(88.0 \%)$ & 1 \\
\hline Chest pain & $3 / 10(30.0 \%)$ & $2 / 25(8.0 \%)$ & 0.13 \\
\hline Abdominal pain & $4 / 10(40.0 \%)$ & $10 / 25(40.0 \%)$ & 1 \\
\hline \multicolumn{4}{|l|}{ Clinical features } \\
\hline Tachycardia & $6 / 9(66.7 \%)$ & $15 / 23(65.2 \%)$ & 1 \\
\hline Tachypnea & $10 / 10(100.0 \%)$ & $23 / 24(95.8 \%)$ & 1 \\
\hline Hypoventilation & $7 / 10(70.0 \%)$ & $20 / 25(80.0 \%)$ & 0.66 \\
\hline Rales & $2 / 10(20.0 \%)$ & $8 / 25(32.0 \%)$ & 0.69 \\
\hline Tubular sounds & $4 / 10(40.0 \%)$ & $7 / 25(28.0 \%)$ & 0.69 \\
\hline Wheezing & $2 / 10(20.0 \%)$ & $1 / 25(4.0 \%)$ & 0.19 \\
\hline $\mathrm{SpO}_{2}<92 \%$ & $1 / 10(10.0 \%)$ & $2 / 19(10.6 \%)$ & 1 \\
\hline
\end{tabular}

Table 2. Results of blood and pleural investigations. Data are expressed as median [range] or n (\%).

\begin{tabular}{|c|c|c|c|}
\hline & Empyema $n=10$ & Empyema + NP $n=25$ & p-value \\
\hline \multicolumn{4}{|l|}{ Blood at admisssion } \\
\hline Hemoglobin $(\mathrm{g} / \mathrm{l})$ & $104[100$ to 130$]$ & $102[79$ to 123$]$ & 0.13 \\
\hline Platelets (G/l) & 328 [237 to 629$]$ & 266 [143 to 999$]$ & 0.08 \\
\hline WBC (G/l) & 18.3 [10.0 to 29.9$]$ & $13.2[0.6$ to 33.8$]$ & 0.22 \\
\hline $\mathrm{WBC}>15 \mathrm{G} / \mathrm{l}$ & $6 / 9(66.7 \%)$ & $10 / 24(41.7 \%)$ & 0.26 \\
\hline CRP (mg/l) & $193[138$ to 200$]$ & $200[60$ to 200$]$ & 0.41 \\
\hline \multicolumn{4}{|l|}{ Pleural fluid } \\
\hline WBC (G/l) & 66.5 [12.1 to 137.6$]$ & $1.1[0.03$ to 72.0$]$ & 0.0002 \\
\hline $\mathrm{pH}$ & $6.8[6.8$ to 7.0$]$ & $7.5[6.4$ to 8.0$]$ & 0.07 \\
\hline $\mathrm{LDH}(\mathrm{U} / \mathrm{l})$ & 18040 [7128 to 31416$]$ & 3138 [586 to 39525$]$ & 0.002 \\
\hline LDH pleura/blood ratio & $63.0[15.1$ to 101.3$]$ & $4.8[2.6$ to 19.5$]$ & 0.0005 \\
\hline Glucose (mmol/l) & $0.8[0.3$ to 1.1$]$ & $1.8[0.3$ to 4.8$]$ & 0.08 \\
\hline Pathogens & $9 / 10$ & $23 / 25$ & \\
\hline Streptococcus pneumoniae & $7 / 9(77.8 \%)$ & $22 / 23(95.7 \%)$ & 0.18 \\
\hline Other Streptococcus & $1 / 9(11.1 \%)$ & $1 / 23(4.3 \%)$ & \\
\hline Staphylococcus aureus ${ }^{*}$ & $1 / 9(11.1 \%)$ & $0 / 0(0.0 \%)$ & \\
\hline
\end{tabular}

WBC: White blood cell count, CRP: C-reactive protein, LDH: lactate dehydrogenase, *: including 1 Methicillin Resistant Staphylococcus aureus. 
Table 3. Management and outcomes. Data are expressed as median [range] or $\mathrm{n}(\%)$.

\begin{tabular}{|c|c|c|c|}
\hline & Empyema $n=10$ & Empyema + NP $n=25$ & p-value \\
\hline \multicolumn{4}{|l|}{ Medical and surgical management } \\
\hline IV $\beta$-lactamines & $10 / 10(100.0 \%)$ & $25 / 25(100.0 \%)$ & 1 \\
\hline Duration $(\mathrm{d})$ & 12.5 [8 to 22$]$ & $12[6$ to 56$]$ & 0.69 \\
\hline Oral $\beta$-lactamines after IV treatment & $10 / 10(100.0 \%)$ & $22 / 24(91.7 \%)$ & 1 \\
\hline Duration (d) & $16[7$ to 30$]$ & $21[9$ to 45$]$ & 0.15 \\
\hline $\mathrm{O}_{2}$ requirement & $7 / 10(70.0 \%)$ & $10 / 25(40.0 \%)$ & 0.15 \\
\hline Duration $(\mathrm{d})$ & $10[2$ to 10$]$ & $8[2$ to 40$]$ & 0.59 \\
\hline Chest tube & $10 / 10(100.0 \%)$ & $24 / 25(96.0 \%)$ & 1.00 \\
\hline Insertion delay after admission (d) & $2[1$ to 15$]$ & $2[0$ to 8$]$ & 0.64 \\
\hline Duration (d) & $7[3$ to 12$]$ & $5[2$ to 128$]$ & 0.67 \\
\hline Intrapleural urokinase & $4 / 5(80.0 \%)$ & $3 / 13(23.1 \%)$ & 0.047 \\
\hline VATS & $8 / 10(80.0 \%)$ & $21 / 25(84.0 \%)$ & 1.000 \\
\hline \multicolumn{4}{|l|}{ Outcomes } \\
\hline Fever duration (d) & 15 [12 to 28$]$ & $14[9$ to 36$]$ & 0.73 \\
\hline Fever duration after admission (d) & $10[3$ to 25$]$ & $9[3$ to 30$]$ & 0.74 \\
\hline ICU admission & $6 / 10(60.0 \%)$ & $12 / 25(48.0 \%)$ & 0.71 \\
\hline ICU length of stay (d) & $3[1$ to 5$]$ & $2[1$ to 33$]$ & 0.92 \\
\hline Hospital length of stay (d) & $15[9$ to 42$]$ & $15[8$ to 140$]$ & 0.71 \\
\hline Delay of X-ray normalization (d) & 288 & 126 & 0.28 \\
\hline
\end{tabular}

IV: intravenous, d: day, VATS: video-assisted thoracoscopic surgery, ICU: intensive Care Unit.

empyema $+\mathrm{NP}$ group, according to the anti-microbial susceptibility testing or in order to treat a secondary infection.

The outcomes are detailed in Table 3. We did not observe any difference between the two groups regarding the fever duration and the ICU or hospital length of stay. Complications occurred in seven patients, but only one $(10 \%)$ in the empyema group, as a secondary pneumatocele requiring thoracoscopy and two chest tubes for 10 days. In the empyema + NP group, complications occurred in five (20\%) patients: one patient presented a pneumothorax during the chest tube removal, one patient required a right superior lobectomy for persistent compressive pneumothorax possibly related to an unconfirmed bronchopleural fistula, and three other patients developed a broncho-pleural fistula. The first one of these last three patients underwent a thoracotomy 89 days after admission and multiple chest tube insertions for a total of 128 days. The second one required two chest tubes for 20 and 26 days. The last one required a chest tube for 19 days. Furthermore, one patient in the empyema + NP group presented a pneumococcal septic shock. No statistical comparison was feasible, considering the small number of patients with complication. Radiological follow-up was available in all patients, and delay of chest X-ray normalization was not different between both groups $(p=0.28)$ (Table 3 and Figure 3 ). 


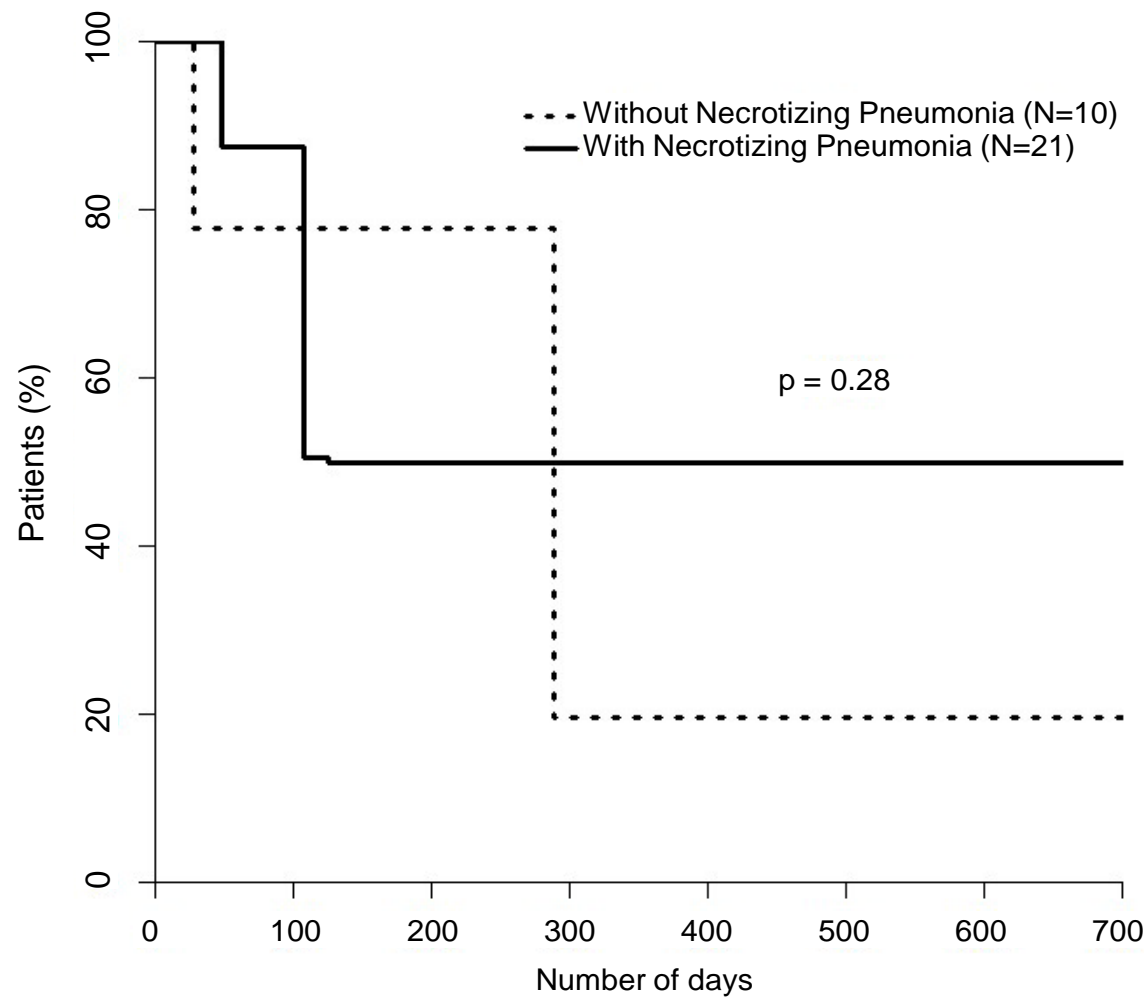

Figure 3. Kaplan-Meier curves of the delay of chest X-ray normalization in the empyema group (dashed line) and the empyema + NP group (solid line) $(\mathrm{p}=0.28)$.

Among the seven patients with complications, the last available X-ray was still abnormal for two of them from the empyema + NP group: the patient requiring a lobectomy (radiological follow-up at 505 days showed a condensation of the right apex) and the patient requiring a thoracotomy (radiological follow-up at 488 days showed blebs in the right apex). Pulmonary function tests were available in five patients from the empyema group and for three patients from the empyema + NP-group, performed between 1 and 12 months after discharge, and were normal.

\section{Discussion}

This paediatric retrospective study aims to evaluate the morbidity effect of concomitant NP in case of empyema. Interestingly, we found similar clinical and biological features, pathogens, management and outcomes in both groups, except for minor biologic parameters in pleural fluid.

Several studies showed that children developing NP were previously healthy [5] [9] [15] [23], and reported no difference in terms of comorbidities and age between patients with simple or complicated pneumonia, including NP [1] [8] [9] [23] [24]. Our results are in accordance with the study of Macedo et al. reporting no difference in age and gender between patients presenting an empyema with or without concomitant NP [18].

Concerning the biological findings, although we did not find any difference in blood inflammatory parameters, WBC tended to be more elevated in the em- 
pyema group as published by Wexler et al. [23]. Ulloa-Gutierrez reported a very high level of $\mathrm{LDH}$ in patients with pneumococcal empyema with concomitant NP, but no value or comparison was available [25]. To our knowledge, no previous study compared pleural findings between patients with empyema associated or not with NP. According to the Light's criteria that differentiate exudative from transudative pleural effusion with three severity stages of inflammation [26] [27], the pleural fluid showed a lower inflammatory level in case of concomitant NP group. These findings concurred with the hypothesis that NP is probably not due to an increased inflammatory process, but is mainly due to an inadequate local leukocyte response, accompanied by vasculitis, gangrene or venous thrombosis [28] [29].

Our results agree with the published data, reporting an increasing predominance of Streptococcus pneumoniae in complicated pneumonia [9] [30]. Staphylococcus aureus infection is reported in $2 \%$ of adult and pediatric community-acquired pneumonia [3] [4] [12], but Lemaitre et al. identified Staphylococcus aureus in $32 \%$ of NP in a pediatric cohort, and all were PVL producers [15]. Against all odds, Staphylococcus aureus was never evidenced in the empyema + NP group, and only in one patient from the empyema group. Since the serotype of Streptococcus pneumoniae was not available in most of our patients, we could not evaluate the potential role of specific serotypes, but we did not observe any difference in anti-pneumococcal vaccination (Prevenar $7^{\circledR}$ ) between the two groups.

The Pediatric Infectious Diseases Society and the Infectious Diseases Society of America recommend to treat hospitalized children with community-acquired pneumonia with an anti-staphylococcal antibiotic in case of clinical, biologic or radiologic suspicion [31]. Moreover, the British Thoracic Society guidelines on pleural infection in children as well as a recent review on pediatric NP recommend to consider Staphylococcus aureus in the treatment strategy [3] [32]. According to our microbiological findings and the limited role of Staphylococcus aureus in complicated pneumonia in previous studies [4] [6], we might reconsider at least in Switzerland to systematically include an anti-staphylococcal treatment as first choice regimen in case of empyema even with concomitant NP. We did not find any difference in terms of antibiotherapy, oxygenotherapy, chest tube requirement/duration or VATS. To our knowledge, the only available recommendations on empyema treatment in children have been published by the British Thoracic Society in 2005 and the Thoracic Society of Australia and New-Zealand in 2011, but without any special focus on empyema associated with NP [32] [33]. Recently the APSA pointed out the lack of data on paediatric empyema management, and recommended caution in case of NP if fibrinolysis/ VATS is necessary due to concomitant pleural space disease [16]. Our management was conducted in agreement with the available recommendations, as medical management was our first line of treatment. Fibrinolytic agents have been prescribed more easily in case of empyema without NP, as this treatment is classically used with caution if not avoided in case of NP. However, in this study, 
a large majority of patients underwent a VATS in a second line after failure of medical management, as recommended by the APSA, and in the same proportion in the two groups [16]. We did not observe any difference in the frequency of VATS between the 2005-2009 and the 2009-2013 periods (data not shown). This is surprising, given that VATS was widely put forward in the early 2000's as a treatment of choice for empyema, but was progressively challenged by the chemical debridement, the fibrinolytic agents and a conservative treatment. Paediatric studies showed contradictory conclusion regarding the surgery (including chest tube, VATS and thoracotomy): one study suggested that surgery was not better than thoracocentesis alone [12], and another supported early VATS as a valuable option to avoid prolonged recovery and late thoracotomy compared to conservative treatment [18]. Since 2008, three randomized studies compared the effectiveness of fibrinolytic agents versus VATS in childhood empyema [34] [35] [36], two of them including also children with concomitant NP [35] [36]. All of them concluded that the two treatments are equivalent and that fibrinolytic treatment is less invasiveness and expensive compared to VATS. Finally, during the last three years, we dramatically decreased the number of VATS in our institution.

Although it has been widely published that complicated pneumonia (e.g. empyema), compared with simple pneumonia, is associated to prolonged hospital length of stay [1] [8] [23], higher rate of complications [1] [6] [8] and delayed clinical and radiological recovery [1] [12] [21], the results regarding the outcomes of empyema with concomitant NP are very few and controversial. One retrospective study specifically reported that empyema associated with NP required a longer hospitalisation than empyema without NP [18], when the sole prospective study showed no difference in hospital length of stay [17], in line with our data. We could not complete the functional follow-up due to the small number of patients, but we found no difference in radiological follow-up between both groups. Krenke et al. showed a complete or almost complete radiological recovery at 6 months post NP [5]. Despite pleural scarring in lung MRI several years after, Honkinen et al. showed a good long-term outcome in case of empyema with rare functional alteration [37].

Chest CT is the accepted gold standard to confirm NP [1] [11] [12]. CT allows earlier and more accurate diagnosis of NP and detects more precisely the parenchymal abnormalities, making CT superior to X-ray or ultra-sound (US) in identifying parenchymal lung diseases [38] [39] [40] [41]. The role of CT in case of empyema has been questioned by Jaffe et al., as these additional findings do not change the management or the outcome of the patient. Thus, the authors concluded that CT should not be performed as a routine investigation for patients with empyema [17]. Used since decades for pleural investigations, US are progressively used for parenchymal analysis given his high accuracy for detecting consolidation and interstitial lung disease. In complicated pneumonia, $\mathrm{Ku}$ rian et al. showed that US was as effective as CT to evaluate pleural fluid, as well as the underlying parenchyma [42]. Other authors showed a high correlation 
between US and CT for NP diagnosis and recommended routine US in case of severe pneumonia [43]. Given the widely recognized radiation-induced risk of malignancy in children [44], it is of importance to assess and clearly confirm the usefulness of CT. Since we found no relevant difference between the 2 groups, we question the usefulness of confirming, by an irradiating chest $\mathrm{CT}$, a suspected concomitant NP in case of empyema. Therefore, we suggest that CT might be restricted to abnormal worsening of pleural empyema or when mandatory for surgical treatment, until it could be eventually replace by US in the future.

We are aware that this study presents several limitations. We included a limited number of patients due to the mono-centric and retrospective nature of the study. In order to detect a difference of hospital length of stay, 89 patients per group would have been necessary to obtain a power of $80 \%$ with an alpha risk of 0.05 , but empyema associated to NP is a rare pathology and no one of the few published studies was able to gather data from a suitable number of patients. Due to the necessity to confirm/infirm NP by a chest CT, considering the poor accuracy of X-ray for detecting NP [17], we clearly selected particularly severe patients especially in our empyema group. This recruitment bias could explain the high proportion of chest tube insertion, fibrinolytic treatment and VATS in this latter group. Furthermore, we did not include a severity scoring of the disease, as the extend of the necrotizing zones, in order to compare patients with extensive necrotizing pneumoniae or with only a small area of necrotizing pneumonia. Finally, we were unable to collect functional follow-up. Indeed, pulmonary function tests after complete recovery would be interesting to study the potential long-term sequela.

\section{Conclusion}

As a conclusion, this paediatric survey is the first study comparing as many parameters in empyema associated or not with $\mathrm{NP}$, and showing no difference regarding risk factors, clinical and biological features, pathogens, management and outcome. Empyema with concomitant NP is rarely due to Staphylococcus aureus, leading to recommend the same empiric antibiotic therapy as empyema without NP. Finally, in case of empyema with suspected concomitant NP, chest CT should probably be restricted to abnormal worsening or when mandatory for surgical treatment.

\section{Acknowledgements}

We are grateful to C. Combescure, from the Clinical Research Centre of the Geneva University, for his assistance with statistical analysis.

\section{References}

[1] Hacimustafaoglu, M., Celebi, S., Sarimehmet, H., Gurpinar, A. and Ercan, I. (2004) Necrotizing Pneumonia in Children. Acta Paediatrica, 93, 1172-1177. https://doi.org/10.1111/j.1651-2227.2004.tb02744.x

[2] Ramphul, N., Eastham, K.M., Freeman, R., Eltringham, G., Kearns, A.M., Leeming, 
J.P., Hasan, A., Hamilton, L.J. and Spencer, D.A. (2006) Cavitatory Lung Disease Complicating Empyema in Children. Pediatric Pulmonology, 41, 750-753. https://doi.org/10.1002/ppul.20434

[3] Spencer, D.A. and Thomas, M.F. (2013) Necrotising Pneumonia in Children. Paediatric Respiratory Reviews, 15, 240-245.

https://doi.org/10.1016/j.prrv.2013.10.001

[4] Tsai, Y.F. and Ku, Y.H. (2012) Necrotizing Pneumonia: A Rare Complication of Pneumonia Requiring Special Consideration. Current Opinion in Pulmonary Medicine, 18, 246-252. https://doi.org/10.1097/MCP.0b013e3283521022

[5] Krenke, K., Sanocki, M., Urbankowska, E., Kraj, G., Krawiec, M., Urbankowski, T., Peradzynska, J. and Kulus, M. (2015) Necrotizing Pneumonia and Its Complications in Children. Advances in Experimental Medicine and Biology, 857, 9-17. https://doi.org/10.1007/5584_2014_99

[6] Erlichman, I., Breuer, O., Shoseyov, D., Cohen-Cymberknoh, M., Koplewitz, B., Averbuch, D., Erlichman, M., Picard, E. and Kerem, E. (2016) Complicated Community Acquired Pneumonia in Childhood: Different Types, Clinical Course, and Outcome. Pediatric Pulmonology. https://doi.org/10.1002/ppul.23523

[7] Donnelly, L.F. and Klosterman, L.A. (1997) Pneumonia in Children: Decreased Parenchymal Contrast Enhancement-CT Sign of Intense Illness and Impending Cavitary Necrosis. Radiology, 205, 817-820. https://doi.org/10.1148/radiology.205.3.9393541

[8] Hsieh, Y.C., Hsueh, P.R., Lu, C.Y., Lee, P.I., Lee, C.Y. and Huang, L.M. (2004) Clinical Manifestations and Molecular Epidemiology of Necrotizing Pneumonia and Empyema Caused by Streptococcus pneumoniae in Children in Taiwan. Clinical Infectious Diseases, 38, 830-835. https://doi.org/10.1086/381974

[9] Tan, T.Q., Mason Jr., E.O., Wald, E.R., Barson, W.J., Schutze, G.E., Bradley, J.S., Givner, L.B., Yogev, R., Kim, K.S. and Kaplan, S.L. (2002) Clinical Characteristics of Children with Complicated Pneumonia Caused by Streptococcus pneumoniae. Pediatrics, 110, 1-6. https://doi.org/10.1542/peds.110.1.1

[10] Hsieh, Y.C., Chi, H., Chang, K.Y., Lai, S.H., Mu, J.J., Wong, K.S., Liu, C.C., Huang, Y.C., Lin, H.C., Chang, L.Y. and Huang, L.M. (2015) Increase in Fitness of Streptococcus pneumoniae Is Associated with the Severity of Necrotizing Pneumonia. Pediatric Infectious Disease Journal, 34, 499-505. https://doi.org/10.1097/INF.0000000000000631

[11] McCarthy, V.P., Patamasucon, P., Gaines, T. and Lucas, M.A. (1999) Necrotizing Pneumococcal Pneumonia in Childhood. Pediatric Pulmonology, 28, 217-221. https://doi.org/10.1002/(SICI)1099-0496(199909)28:3<217::AID-PPUL9>3.0.CO;2$\underline{\mathrm{R}}$

[12] Sawicki, G.S., Lu, F.L., Valim, C., Cleveland, R.H. and Colin, A.A. (2008) Necrotising Pneumonia Is an Increasingly Detected Complication of Pneumonia in Children. European Respiratory Journal, 31, 1285-1291. https://doi.org/10.1183/09031936.00099807

[13] El Choueiry, E., Cuzon, G., Dugelay, F., Chevret, L., Durand, P. and Bergounioux, J. (2011) [Necrotizing Community-Acquired Staphylococcus aureus Pneumonia]. Archives de Pédiatrie, 18, 767-771. https://doi.org/10.1016/j.arcped.2011.04.004

[14] Kreienbuehl, L., Charbonney, E. and Eggimann, P. (2011) Community-Acquired Necrotizing Pneumonia Due to Methicillin-Sensitive Staphylococcus aureus Secreting Panton-Valentine Leukocidin: A Review of Case Reports. Annals of Intensive Care, 1, 52. https://doi.org/10.1186/2110-5820-1-52

[15] Lemaitre, C., Angoulvant, F., Gabor, F., Makhoul, J., Bonacorsi, S., Naudin, J., Al- 
ison, M., Faye, A., Bingen, E. and Lorrot, M. (2013) Necrotizing Pneumonia in Children: Report of 41 Cases between 2006 and 2011 in a French Tertiary Care Center. Pediatric Infectious Disease Journal, 32, 1146-1149. https://doi.org/10.1097/INF.0b013e31829be1bb

[16] Islam, S., Calkins, C.M., Goldin, A.B., Chen, C., Downard, C.D., Huang, E.Y., Cassidy, L., Saito, J., Blakely, M.L., Rangel, S.J., Arca, M.J., Abdullah, F. and St Peter, S.D. (2012) The Diagnosis and Management of Empyema in Children: A Comprehensive Review from the APSA Outcomes and Clinical Trials Committee. Journal of Pediatric Surgery, 47, 2101-2110. https://doi.org/10.1016/j.jpedsurg.2012.07.047

[17] Jaffe, A., Calder, A.D., Owens, C.M., Stanojevic, S. and Sonnappa, S. (2008) Role of Routine Computed Tomography in Paediatric Pleural Empyema. Thorax, 63, 897902. https://doi.org/10.1136/thx.2007.094250

[18] Macedo, M., Meyer, K.F. and Oliveira, T.C. (2010) Necrotizing Pneumonia in Children Submitted to Thoracoscopy Due to Pleural Empyema: Incidence, Treatment and Clinical Evolution. Jornal Brasileiro de Pneumologia, 36, 301-305. https://doi.org/10.1590/S1806-37132010000300006

[19] Suchar, A.M., Zureikat, A.H., Glynn, L., Statter, M.B., Lee, J. and Liu, D.C. (2006) Ready for the Frontline: Is Early Thoracoscopic Decortication the New Standard of Care for Advanced Pneumonia with Empyema? American Surgeon, 72, 688-692.

[20] Hardie, W., Bokulic, R., Garcia, V.F., Reising, S.F. and Christie, C.D. (1996) Pneumococcal Pleural Empyemas in Children. Clinical Infectious Diseases, 22, 10571063. https://doi.org/10.1093/clinids/22.6.1057

[21] Donnelly, L.F. and Klosterman, L.A. (1998) Cavitary Necrosis Complicating Pneumonia in Children: Sequential Findings on Chest Radiography. American Journal of Roentgenology, 171, 253-256. https://doi.org/10.2214/ajr.171.1.9648799

[22] Lindsey, J.C. and Ryan, L.M. (1998) Tutorial in Biostatistics Methods for Interval-Censored Data. Statistics in Medicine, 17, 219-238. https://doi.org/10.1002/(SICI)1097-0258(19980130)17:2<219::AID-SIM735>3.0.CO; $\underline{2-\mathrm{O}}$

[23] Wexler, I.D., Knoll, S., Picard, E., Villa, Y., Shoseyov, D., Engelhard, D. and Kerem, E. (2006) Clinical Characteristics and Outcome of Complicated Pneumococcal Pneumonia in a Pediatric Population. Pediatric Pulmonology, 41, 726-734. https://doi.org/10.1002/ppul.20383

[24] Pande, A., Nasir, S., Rueda, A.M., Matejowsky, R., Ramos, J., Doshi, S., Kulkarni, P. and Musher, D.M. (2012) The Incidence of Necrotizing Changes in Adults with Pneumococcal Pneumonia. Clinical Infectious Diseases, 54, 10-16. https://doi.org/10.1093/cid/cir749

[25] Ulloa-Gutierrez, R. (2008) Pneumococcal Necrotizing Pneumonia and Pleural Fluid Lactate Dehydrogenase Level. Clinical Infectious Diseases, 47, 729-730. https://doi.org/10.1086/590974

[26] Light, R.W., Macgregor, M.I., Luchsinger, P.C. and Ball, W.C. (1972) Pleural Effusions: The Diagnostic Separation of Transudates and Exudates. Annals of Internal Medicine, 77, 507-513. https://doi.org/10.7326/0003-4819-77-4-507

[27] Light, R.W. (2006) Parapneumonic Effusions and Empyema. Proceedings of the. American Thoracic Society, 3, 75-80. https://doi.org/10.1513/pats.200510-113JH

[28] Schadeck, T., Beckers, D., Eucher, P., de Bilderling, G., Tuerlinckx, D. and Bodart, E. (2006) [Necrotizing Pneumonia in Children: Apropos of 4 Cases]. Archives de Pédiatrie, 13, 1209-1214. https://doi.org/10.1016/j.arcped.2006.04.015

[29] Tuomanen, E.I., Austrian, R. and Masure, H.R. (1995) Pathogenesis of Pneumo- 
coccal Infection. New England Journal of Medicine, 332, 1280-1284. https://doi.org/10.1056/NEJM199505113321907

[30] Chibuk, T.K., Robinson, J.L. and Hartfield, D.S. (2010) Pediatric Complicated Pneumonia and Pneumococcal Serotype Replacement: Trends in Hospitalized Children Pre and Post Introduction of Routine Vaccination with Pneumococcal Conjugate Vaccine (PCV7). European Journal of Pediatrics, 169, 1123-1128. https://doi.org/10.1007/s00431-010-1195-6

[31] Bradley, J.S., Byington, C.L., Shah, S.S., Alverson, B., Carter, E.R., Harrison, C., Kaplan, S.L., Mace, S.E., McCracken, G.H., Moore, M.R., St Peter, S.D., Stockwell, J.A. and Swanson, J.T. (2011) The Management of Community-Acquired Pneumonia in Infants and Children Older than 3 Months of Age: Clinical Practice Guidelines by the Pediatric Infectious Diseases Society and the Infectious Diseases Society of America. Clinical Infectious Diseases, 53, e25-e76. https://doi.org/10.1093/cid/cir531

[32] Balfour-Lynn, I.M., Abrahamson, E., Cohen, G., Hartley, J., King, S., Parikh, D., Spencer, D., Thomson, A.H. and Urquhart, D. (2005) BTS Guidelines for the Management of Pleural Infection in Children. Thorax, 60, i1-i21. https://doi.org/10.1136/thx.2004.030676

[33] Strachan, R.E. and Jaffe, A. (2011) Recommendations for Managing Paediatric Empyema Thoracis. Medical Journal of Australia, 195, 95.

[34] St Peter, S.D., Tsao, K., Spilde, T.L., Keckler, S.J., Harrison, C., Jackson, M.A., Sharp, S.W., Andrews, W.S., Rivard, D.C., Morello, F.P., Holcomb, G.W. and Ostlie, D.J. (2009) Thoracoscopic Decortication vs Tube Thoracostomy with Fibrinolysis for Empyema in Children: A Prospective, Randomized Trial. Journal of Pediatric Surgery, 44, 106-111. https://doi.org/10.1016/j.jpedsurg.2008.10.018

[35] Sonnappa, S., Cohen, G., Owens, C.M., van Doorn, C., Cairns, J., Stanojevic, S., Elliott, M.J. and Jaffe, A. (2006) Comparison of Urokinase and Video-Assisted Thoracoscopic Surgery for Treatment of Childhood Empyema. American Journal of Respiratory and Critical Care Medicine, 174, 221-227. https://doi.org/10.1164/rccm.200601-027OC

[36] Marhuenda, C., Barcelo, C., Fuentes, I., Guillen, G., Cano, I., Lopez, M., Hernandez, F., Perez-Yarza, E.G., Matute, J.A., Garcia-Casillas, M.A., Alvarez, V. and MorenoGaldo, A. (2014) Urokinase versus VATS for Treatment of Empyema: A Randomized Multicenter Clinical Trial. Pediatrics, 134, e1301-e1307.

https://doi.org/10.1542/peds.2013-3935

[37] Honkinen, M., Lahti, E., Svedstrom, E., Jartti, T., Virkki, R., Peltola, V. and Ruuskanen, O. (2014) Long-Term Recovery after Parapneumonic Empyema in Children. Pediatric Pulmonology, 49, 1020-1027.

https://doi.org/10.1002/ppul.22966

[38] Donnelly, L.F. and Klosterman, L.A. (1998) The Yield of CT of Children Who Have Complicated Pneumonia and Noncontributory Chest Radiography. American Journal of Roentgenology, 170, 1627-1631.

https://doi.org/10.2214/ajr.170.6.9609186

[39] Hodina, M., Hanquinet, S., Cotting, J., Schnyder, P. and Gudinchet, F. (2002) Imaging of Cavitary Necrosis in Complicated Childhood Pneumonia. European Radiology, 12, 391-396. https://doi.org/10.1007/s003300101008

[40] Kosucu, P., Ahmetoglu, A., Cay, A., Imamoglu, M., Ozdemir, O., Dinc, H., Sarihan, H., Gumele, H.R. (2004) Computed Tomography Evaluation of Cavitary Necrosis in Complicated Childhood Pneumonia. Australasian Radiology, 48, 318-323. https://doi.org/10.1111/j.0004-8461.2004.01314.x 
[41] Tan Kendrick, A.P., Ling, H., Subramaniam, R. and Joseph, V.T. (2002) The Value of Early CT in Complicated Childhood Pneumonia. Pediatric Radiology, 32, 16-21. https://doi.org/10.1007/s00247-001-0583-5

[42] Kurian, J., Levin, T.L., Han, B.K., Taragin, B.H. and Weinstein, S. (2009) Comparison of Ultrasound and CT in the Evaluation of Pneumonia Complicated by Parapneumonic Effusion in Children. American Journal of Roentgenology, 193, 1648 1654. https://doi.org/10.2214/AJR.09.2791

[43] Lai, S.H., Wong, K.S. and Liao, S.L. (2015) Value of Lung Ultrasonography in the Diagnosis and Outcome Prediction of Pediatric Community-Acquired Pneumonia with Necrotizing Change. PLoS ONE, 10, e0130082.

https://doi.org/10.1371/journal.pone.0130082

[44] Miglioretti, D.L., Johnson, E., Williams, A., Greenlee, R.T., Weinmann, S., Solberg, L.I., Feigelson, H.S., Roblin, D., Flynn, M.J., Vanneman, N. and Smith-Bindman, R. (2013) The Use of Computed Tomography in Pediatrics and the Associated Radiation Exposure and Estimated Cancer Risk. JAMA Pediatrics, 167, 700-707.

https://doi.org/10.1001/jamapediatrics.2013.311

Submit or recommend next manuscript to SCIRP and we will provide best service for you:

Accepting pre-submission inquiries through Email, Facebook, LinkedIn, Twitter, etc. A wide selection of journals (inclusive of 9 subjects, more than 200 journals)

Providing 24-hour high-quality service

User-friendly online submission system

Fair and swift peer-review system

Efficient typesetting and proofreading procedure

Display of the result of downloads and visits, as well as the number of cited articles

Maximum dissemination of your research work

Submit your manuscript at: http://papersubmission.scirp.org/

Or contact health@scirp.org 